\title{
ASSESSMENT OF THE BLACK SEA SHELF ECOSYSTEM SUSTAINABILITY WITH MATHEMATICAL SIMULATION METHOD
}

\author{
Viktor KOMORIN ${ }^{1}$ (D)
}

DOI: 10.21163/GT_2020.162.02

\begin{abstract}
:
The system analysis approach has been used for assessment of the sustainability of the marine shelf ecosystem with the method of mathematical modeling on the example of the north-western shelf of the Black Sea, as the most vulnerable part of the sea to the influence of natural and anthropogenic factors. Based on numerical experiments, an analysis of ecosystem risk in dynamic phase space was performed. Results have shown that the ecosystem risk of the Black Sea shelf zone has fluctuated around baseline value over the last decade under the existing influences of natural and anthropogenic factors, but the system approaches an unstable state with an increase of the combined effects of natural and anthropogenic factors.
\end{abstract}

Key-words: system analysis, ecosystem risk, marine ecosystem, mathematical modeling, ecosystem stability, Black Sea.

\section{INTRODUCTION}

The Black Sea is a unique body of water, eighty-seven percent of which is hydrogen sulfide. The upper layer of water remains suitable for the life of oxygen organisms, the thickness of which has been decreasing over the last decades. It may be about 60 meters in the central regions of the sea (Slobodnik J. et al.2020a). Any sufficiently powerful external influence, whether anthropogenic or natural ones can affect the stability of marine ecosystems. Anthropogenic problems of the Black Sea are formed and most acutely manifested in the coastal and shelf zone of the seas. Here there are a high level of economic activity and so many marine sources of pollution. The most significant impact of human activities on marine ecosystems exercise regulation of river flow, the activity of ports including works of dredging in the port waters and approach channels, dumping soil, exploration, and production of hydrocarbon resources, environmentally unjustified intensification of resource and service sectors in the marine and coastal waters, including fishing and other seafood, uncontrolled industrialization, chemicals, urbanization coast. These activities led to an unacceptable increase in marine pollution domestic, industrial, agricultural and other waste containing hazardous and harmful substances and pathogens.

The Northwestern Black Sea shelf is the most environmentally sensitive area of the Black Sea (Slobodnik et al., 2020b, 2020c). This was indicated with assessment data of the ecosystem of the Black Sea to 8 descriptors MSFD (Directive 2008/56 / EC of the European Parliament and of the Council of 17 June 2008 establishing a framework for community action in the field of marine environmental policy (Marine Strategy Framework Directive) presented in reports Draft EU / UNDP Project: Improving Environmental Monitoring in the Black Sea - Phase II (EMBLAS-II) ENPI / 2013 / 313-169 (Slobodnik et al., 2020a, 2020b, 2020c). A typical illustration of the assessment is represented in Fig. 1 for BEAST (Slobodnik et al. 2020c). The biggest problems of the Black Sea are eutrophication, biodiversity loss, toxic pollution, etc. (BS EEA, 2015). This paper examines the impact of electrification, exacerbated by climate change, on the resilience of the marine shelf ecosystem in the field of ecological, economic, social systems.

\footnotetext{
${ }^{1}$ Research Institution "Ukrainian Scientific Centre of Ecology of the Sea", Odesa, 65009, Ukraine, vkomorin@gmail.com
} 
This concept combines the human-nature systems and their components through ecosystem services and the factors of influence. It's arising from the direct use of services, as the indirect influence through human activities in general (Maes et al., 2016). Ecosystem function is defined as the capacity to provide ecosystem services (De Groot, 2010). Ecosystem services, in turn, derive from ecosystem functions and represent flows of services for which there is demand. For this concept, ecosystem services also cover products derived from these ecosystems (Edward and Barbier, 2017). Ecosystem services of the sea and coastal zones are considered within the issues of biodiversity conservation, use of water resources, conservation/ restoration of marine ecosystems, climate regulation, agriculture (Liquete et al., 2013).

The ability to provide ecosystem services regularly is depended on the stability of the system and its vulnerability to the effects. This can be analyzed through mathematical modeling of ecosystem risk within the theory of dynamical systems. The history of the use of ecological models goes back to the main work of Robert May (May, 1974). Historically, the use of mathematical models in ecology has been based on the use of tools that require fewer data and are easier to use in management decisions. Modern methods allow the use of models describing ecosystem components in more detail (Fulford, Heymans and Wei Wu, 2020).

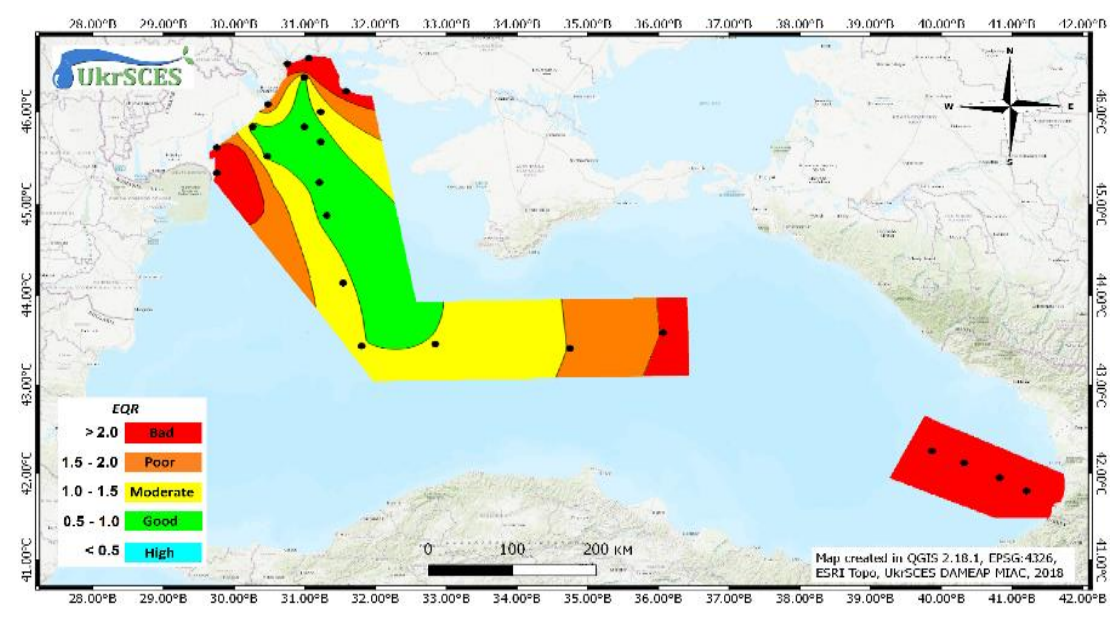

Fig. 1. Indicative assessment of environmental and ecological status of the Black Sea areas investigated during the JOSS 2019 based on eutrophication indicator BEAST index EQR (Slobodnik et al. 2020c, URL: http://emblasproject.org/wp-content/uploads/2019/07/EMBLASII_NPMS_JOSS_2017_ScReport_FinDraft2.pdf).

Objective scientifically-based forecasting of ecological consequences of the impact on the marine environment of functioning and planned economic objects, estimation of efficiency of various administrative decisions in the field of rational use, protection, and restoration of resources of a shelf zone of the sea are impossible without the use of mathematical models of the formation of quality of waters of marine ecosystems ( Addison et al., 2018). Creation and verification of such models, for their application as a tool of ecological forecasting in the course of scenario modeling of natural processes, is one of the main tasks of environmental monitoring of coastal marine waters. Examples of the application of mathematical models for solving diagnostic and prognostic problems of the marine ecosystem and its components for the shelf areas of the Black Sea can be found in the following works (Tuchkovenko et al., 2005; Komorin and Tuchkovenko, 2002; Komorin et al., 2008; Komorin et al., 2017; Orlova I. et al., 2005). One of the models that allow analyzing changes in aquatic ecosystems under the influence of anthropogenic factors is AQUATOX (AQUATOX, 2018). This model has been successfully used to measure human impact on the Black Sea, for example, in the work specified in the references (Şimşek et al., 2019). There are several groups of requirements for 
biological systems according to the definition of "sustainability" (Svirezhev, 1974; Odum, Eugene P., 1953). First, the time invariance of a geographic area or landscape. The region can include a wide variety of biocenosis, the total ecosystem of the region, poorly connected. The main processes that determine the dynamics of the region indicators will not change the number of species inhabiting its individual and global biogeochemical cycles.

The second group of requirements is the preservation of the number of species in a biological community. The biological community is the higher level of organization of living matter than the population. It should be defined as a set of populations that inhabits the area and forms the structure of food (trophic) links and metabolism. The concept of the biological community reflects that populations of living organisms are not randomly scattered across the Earth as independent groups, but form organized systems. A community is sustainable if the number of its constituent species does not change over time. This ecological definition is the closest to the various definitions of sustainability.

The third group of requirements applies to individual populations rather than communities. It is considered that a community is stable or stable if the numbers of its constituent populations do not fluctuate sharply. In thermodynamics, a system is stable if there are small probabilities of large fluctuations that can take it far from equilibrium and even destroy it.

On the other hand, there is a developed mathematical theory of stability, in which the definition of stability is given exhaustively (Polderman and Willems, 1998). But this theory does not work with the real objects, but with their mathematical models. Therefore, if we have a sufficiently "good" (in the sense of adequacy and completeness of description) mathematical model of a biological community or ecosystem (for example, in terms of differential or difference equations), then the question of the stability of a real community can be answered by examining our model stability. In mathematical theory, there are several concepts of stability of motion: Lyapunov stability, asymptotic stability, orbital stability, Poisson stability, Lagrange stability. One of the main ones is Lyapunov's resilience. For sustainable movement on Lyapunov the small initial shift increases. If the small initial shift not only increases, and eventually goes to zero, the movement has robust property of asymptotic stability.

The concept of orbital stability does not consider the distance between the points of the original and perturbed trajectories at the same time, and the minimum distance from the depicting point of the perturbed trajectory to the orbit corresponding to the original motion. Orbitally stable motion may not be stable according to Lyapunov. Non-stationary states of the system are possible, i.e. those in which the equilibrium state does not have time to be established. Increasing nonlinearity in the system beyond some critical value again leads the system to bifurcation: macroscopic consistency is replaced by the inconsistency of random fluctuations, which leads to ambiguous results: a small change in the initial condition over time leads to arbitrarily large changes in system dynamics. In this situation, the system is characterized by instability with its initial parameters (Lyapunov instability) and an exponential tendency to divergence. This behavior of systems was assigned the term dynamic.

Unambiguous characteristics of signal chaos are the spectrum of Lyapunov parameters. The positive maximum Lyapunov index is a measure of chaotic dynamics, zero Lyapunov exponents indicate the maximum limit cycle or quasi-periodic orbit and the negative maximum Lyapunov exponent is a fixed point. The system of dimension $n$ has $n$ Lyapunov exponents: $\lambda_{1}, \lambda_{2}, \ldots, \lambda_{n}$, ordered in descending order. Dynamic systems for which the n-dimensional phase volume decreases are called dissipative. If the phase volume is maintained, then such systems are called conservative. Conservative system always has at least one conservation law. The existence of the conservation law often leads to the existence of a corresponding Lyapunov zero. For dissipative dynamical systems, the sum of Lyapunov exponents is always negative. In dissipative systems, Lyapunov indices are invariant under all initial conditions. The attractor is the most important concept that captures the specifics of dissipative structures. In fact, attractor can be considered as a factor of order (the order parameter for the system in the process of self-organization) (Nikolis and Prigogine, 1989). In terms of Lyapunov much can be said about the dynamic system, as there is a mode of attractor dimension if any, and the entropy of a dynamical system. Dynamic chaos instability corresponds to each 
trajectory, i.e. the presence of at least one positive Lyapunov exponent. Attraction to the attractor requires that large-volume phase volumes be compressed, as reflected in the Lyapunov spectrum. Knowledge of Lyapunov parameters allows us to estimate the fractal dimension of the attractor.

The purpose of this study is to evaluate the stability of the dynamics of the marine ecosystem of the Black Sea under the influence of natural and anthropogenic factors on ecosystem-based analysis of the dynamics of risk in dynamic phase space using models AQUATOX. The objects of research are the ecosystem of coastal waters of the Black Sea and natural and anthropogenic factors of influence. The subject of the study is indicators of the state of the marine ecosystem and indicators of influencing factors. The research methods are comparative analysis and the method of mathematical modeling of the dynamics of the marine ecosystem.

\section{MATERIALS AND METHODS}

Assessing the impact of natural and anthropogenic factors on the quality of coastal waters of the Black Sea held with the model AQUATOX, which is well suited for the analysis of causes and occurrence of eutrophication (Park and Clough, 2003). Possible applications include consideration of water quality criteria for organic matter and analysis of management alternatives. AQUATOX simulates many interrelated variables important in the dynamics of dissolved oxygen, and their impact on the aquatic environment: nitrogen (total, nitrate, ammonia ions, and compounds;

phosphorus (total amount, phosphates); dissolved oxygen; algal biomass, chlorophyll; periphyton biomass; macrophytes; transparency. Table 1 shows the main types of organisms that are included in the model.

Table 1. The main species of organisms taken into account in the mathematical model
of the ecosystem of the Black Sea Coastal Zone (BSCZ)

\begin{tabular}{|l|l|l|}
\hline \multirow{4}{*}{ Organism } & $\begin{array}{l}\text { The name of the organism characteristic } \\
\text { BSCZ }\end{array}$ & $\begin{array}{l}\text { The name of the organism, or its analogues } \\
\text { in the AQUATOX library }\end{array}$ \\
\hline \multirow{5}{*}{ Phytoplankton } & Diatom & Diatom \\
\cline { 2 - 3 } & Green algae & Greens \\
\cline { 2 - 3 } & Blue-green algae & Bl-Greens \\
\cline { 2 - 3 } & Dinophytic algae & Dinoflagellate \\
\cline { 2 - 3 } & Golden algae & Chrysophyta \\
\hline \multirow{5}{*}{ Zooplankton } & Paddlefish & Copepoda \\
\cline { 2 - 3 } & Branchiopoda & Cladocera \\
\cline { 2 - 3 } & Rotifers & Rotifera \\
\cline { 2 - 3 } & Predatory zooplankton & Predatory Zooplankton \\
\hline \multirow{5}{*}{ Fishes } & Polychaetes & Polychaete \\
\cline { 2 - 3 } & Amphipods & Amphipod \\
\cline { 2 - 3 } & Mussels & Mussel \\
\cline { 2 - 3 } & Gastropods & Gastropod \\
\hline & Anchovy & Anchovy (Hamsa) \\
\cline { 2 - 3 } & Sprat & Sprats \\
\cline { 2 - 3 } & Horse mackerel & Horse-mackerel \\
\cline { 2 - 3 } & Goby & Goby \\
\hline
\end{tabular}

Characteristics of phytoplankton and zooplankton, input data of temperature, salinity, nutrients in AQUATOX was set according to data of the Ukrainian Scientific Center of Ecology of the Sea (UkrSCES) (see Fig. 2), which are presented in the reports on the website of the institution http://www.sea.gov.ua/ ? $\mathrm{p}=1215$. 


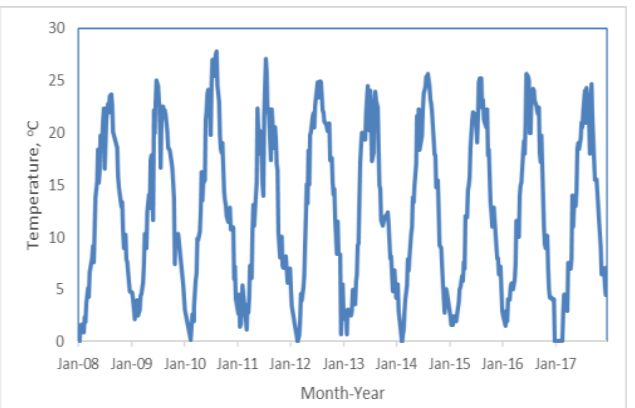

Month-Year

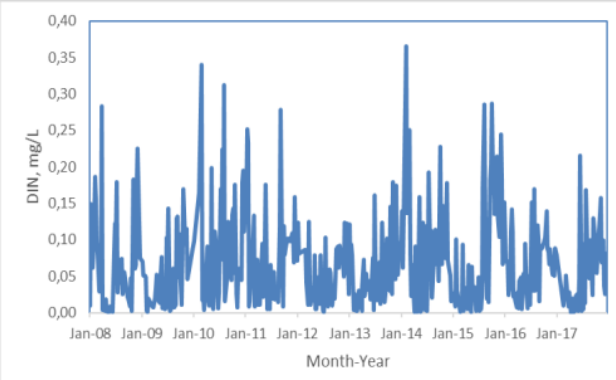

Month-Year

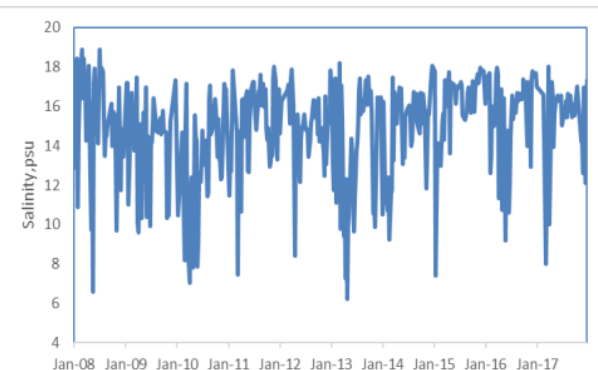

Month-Year

a)

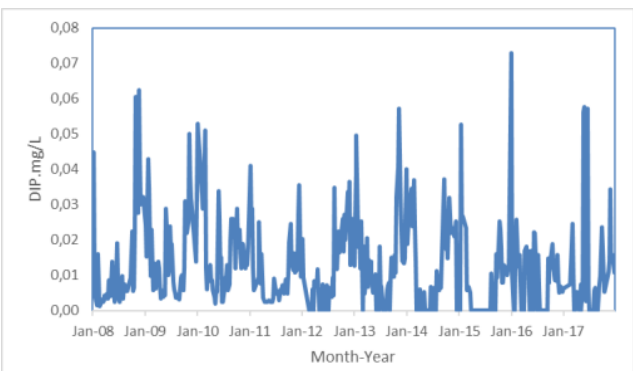

d)

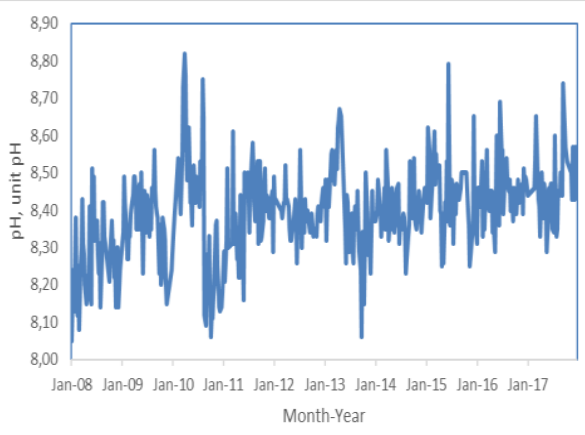

e)

Fig. 2. Long-term changes in temperature - (a), salinity - (b), concentration of the mineral forms of phosphorus (DIP) - (c) and nitrogen (DIN) - (d) and pH - (e), (2008 - 2018, UkrSCES).

The quality of model calculations is evaluated based on the ratio $\mathrm{S} / \sigma$, where $\sigma$ - is the standard deviation, which is determined for the analyzed series of values of the concentration of the substance by the formula:

$$
\sigma=\sqrt{\frac{\Sigma\left(C_{j}\right)^{2}-\frac{\left(\sum C_{j}\right)^{2}}{n}}{n-1}},
$$

$S$ - mean-square error of test results calculated values of concentration of the substance found in the regression equation, which is defined by the formula:

$$
S=\sqrt{\frac{\sum\left(C_{j}-C_{m}\right)^{2}}{n-2}},
$$


where $C_{m}$ - is the value of the concentration of the substance obtained from the equation of the model according to the data of water flow in the watercourse, at which $C_{j}$ was recorded.

\section{CALCUlation}

Using the model was assessed the stability of the dynamics of the marine ecosystem of the Black Sea carried out for the period from 2008 to 2018 in this UkrSCES. To quantify the impact of natural and anthropogenic factors on the state of marine shelf ecosystems, we use the ecosystem risk, which can be expressed as a function of the relationship of influencing factors with ecosystem status parameters in Euclidean space used in (Komorin et al. 2015):

$$
R=\sqrt{E^{2}+C^{2}}
$$

where $\mathrm{E}-$ is an integral factor of influence;

$\mathrm{C}-$ is an integral indicator of the state of the ecosystem.

In general, the integral factor of influence is determined by:

$$
E=\frac{\sum_{i}^{N} e_{i}}{N}
$$

where $e_{i}-$ is an indicator of the $i$-th factor of influence, which is the normalized value of the deviation of the factor from the norm to the maximum amplitude of oscillations;

$\mathrm{N}$ - the number of influencing factors.

The integrated state indicator is calculated with a similar formula. Modeling coastal ecosystems of the Black Sea held in diagnostic mode. At the same time, the factors influencing the state of the ecosystem were determined during the period of 2008 - 2018 every week by UkrSCES in Odessa Bay (Malyi Fontan). The main indicator of Lyapunov characterizes the degree of exponential divergence of close trajectories. The presence of a positive exponent of Lyapunov in the system indicates that any two close trajectories diverge rapidly over time, i.e. there is a sensitivity to the values of the initial conditions. Therefore, the definition of the exponent Lyapunov allows us to identify a dynamic system in terms of the presence of chaotic behavior. Lyapunov indicators were calculated to study the stability of the marine biocenosis. The TISEAN system was used for calculations (TISEAN 3.0.1, 2018).

\section{RESULTS AND DISCUSSION}

In Table 2 according to the results of (Komorin et al., 2015) the results of the quality assessment of model calculations are given. As factors of influence were considered indicators that depend more on natural factors of influence - the temperature and salinity of seawater; anthropogenic concentrations of nutrients and $\mathrm{pH}$. The temporal dynamics of ecosystem risk are presented in Fig. 3 . The upper limit of the confidence interval for the arithmetic mean of the ecosystem risk during 2008 - 2018 was taken as a critical value (arithmetic mean plus standard deviation). The results of the calculation of ecosystem risk according to formula (3) in the plane of the dependence of the ecosystem on the factors of influence are presented in Fig. 4. The values of risk, which are located in the red zone are critical. 
Parameters for assessing the quality of model calculations

Table 2.

\begin{tabular}{|l|l|}
\hline Indicators & S/ \\
\hline Nitrates & 0.21 \\
\hline Salinity & 0.22 \\
\hline Phosphates & 0.23 \\
\hline Oxygen & 0.24 \\
\hline Ammonium nitrogen & 0.25 \\
\hline Dinophytes & 0.35 \\
\hline Greens & 0.56 \\
\hline Blue-Green & 0.60 \\
\hline Diatoms & 0.70 \\
\hline Total zooplankton & 0.71 \\
\hline
\end{tabular}

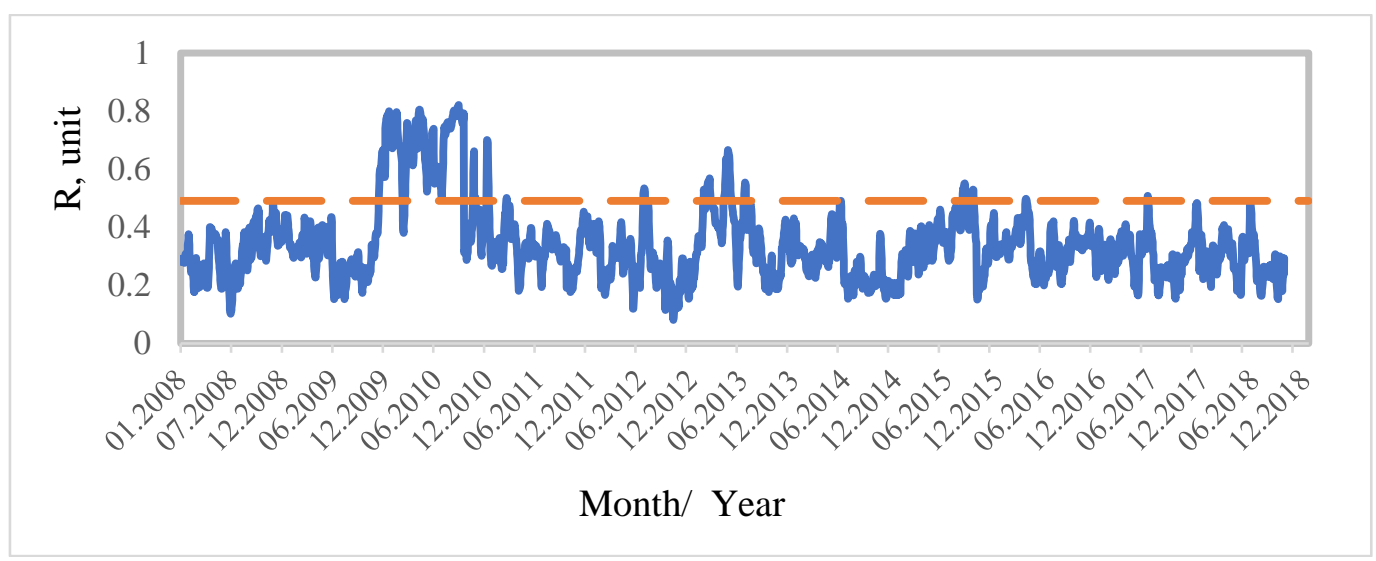

Fig. 3. Temporal dynamics of ecosystem risk (R) for the period 2008-2018.

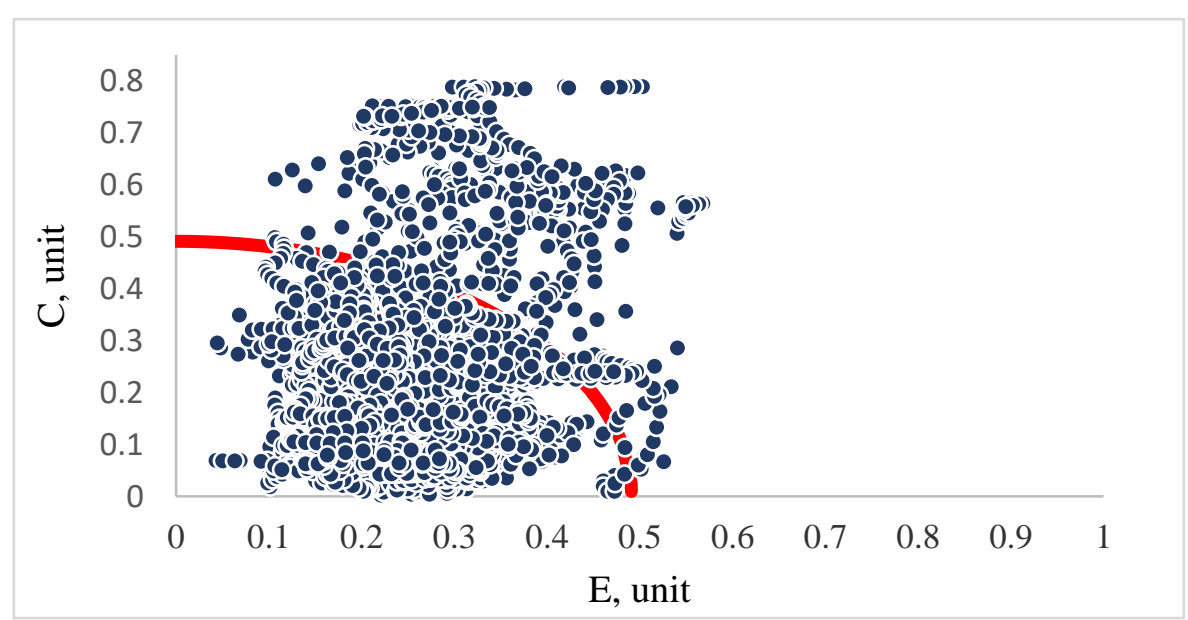

Fig. 4. Estimated values of ecosystem risk in the planes and the dependence of the state of the ecosystem (C) on the sum of factors (E). 
As can be seen from Fig. 3 and Fig. 4, points corresponding to the spring period have entered the zone beyond the red line of critical risk. Thus, the results obtained for the last ten years show that the marine ecosystem of Odessa Bay was in crisis at the end of winter and in summer. Analysis of the dynamics of ecosystem risk in the dynamic phase space shows that the ecosystem after external influence seeks to maintain the initial values (see Fig. 5). In other words, changes in the biotic structure of the ecosystem and the intensity of changes in biomass in response to changes in environmental conditions are aimed at maintaining the optimal balance in the new conditions.

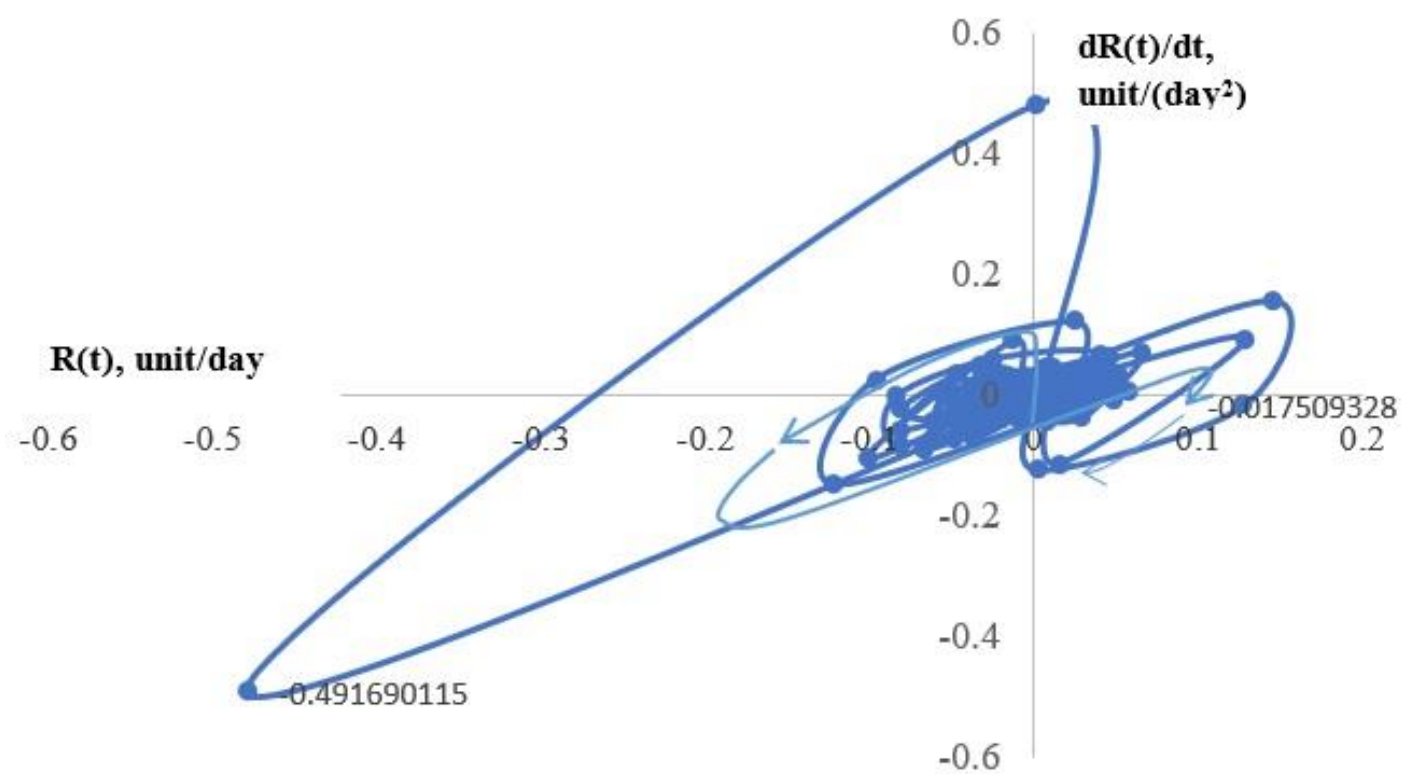

Fig. 5. Dynamics of ecosystem risk $(\mathrm{R})$ in phase space: $\mathrm{R}(\mathrm{t})$ and $\mathrm{dR}(\mathrm{t}) / \mathrm{dt}(\mathrm{t}-\mathrm{time}$ in days).

Estimation of the maximum Lyapunov exponent $\lambda$, which characterizes the velocity of divergence of close trajectories of dynamics in the phase space, allows us to conclude the stability of the ecosystem under the influence of certain factors. A positive value of the indicator is usually taken as an indicator of system instability. The analysis showed that the system approaches an unstable state with an increase in nutrients 5 times the norm, as well as a result of the combined effects of natural (changes in temperature and salinity of seawater) and anthropogenic factors (increase in nutrients at least 2 times). For the period from 2008 to 2018 , the Lyapunov index $\lambda$ varies from $(-0.04)$ to $(-0.001)$. Since $\lambda<0$, this means that such a system does not show signs of instability.

\section{CONCLUSIONS}

A system analysis approach has been used for a comprehensive assessment of the impact of natural and anthropogenic factors on the resilience of coastal ecosystems of the Black Sea was conducted with the ecosystem risk and mathematical modeling on the AQUATOX. Modeling of the Black Sea coastal water ecosystem was carried out in diagnostic mode. The factors influencing on the state of the ecosystem were determined during the period 2008 - 2018 based on weekly measurements of the UkrSCES in Odessa Bay (Maly Fontan). The ecosystem risk indicator was used to quantify the impact of natural and anthropogenic factors on the state of marine shelf ecosystems. It was represented as a function of the relationship of influencing factors with ecosystem status parameters in Euclidean space.

As indicators reflecting the effect of environmental factors impact on the marine ecosystem considered the temperature and salinity of seawater, anthropogenic - nutrients, and $\mathrm{pH}$. In the plane 
of distribution of ecosystem risk by factors of condition and impact in the critical risk zone, some points correspond to the winter-spring and summer periods of the year. The paper identifies indicators of the sustainability of the ecological system over ten years.

Analysis of the dynamics of ecosystem risk in the dynamic phase space shows that the ecosystem afterward external influence seeks to maintain its original values. In other words, the change in the biological structure of the ecosystem and the intensity of changes in the state of the ecosystem in response to changes in environmental conditions are aimed at maintaining the optimal balance in the existing conditions. The largest changes in ecosystem risk correspond to the same winter-spring and summer periods of the year.

Estimation of the maximum Lyapunov exponent $\lambda$, which characterizes the velocity of divergence of close trajectories of dynamics in the phase space, allowed us to conclude the stability of the ecosystem under the influence of certain factors. The analysis showed that the system approaches an unstable state with an increase in nutrients 5 times the norm, as well as a result of the combined effects of natural (changes in temperature and salinity of seawater) and anthropogenic factors (increase in nutrients at least 2 times). For the model diagnostic period from 2008 to 2018, the Lyapunov index $\lambda$ varies from (-0.04) to (-0.001), i.e. it is less than zero, which means that the system is in a stable state.

\section{REFERENCES}

AQUATOX. (2018) Linking water quality and aquatic life. [Online] Available from: https://www.epa.gov/ceam/aquatox. [Accessed 19 ${ }^{\text {th }}$ August 2019]

BS EEA. (2015) Black Sea region briefing - The European environment — state and outlook 2015. [Online] Available from: https://www.eea.europa.eu/soer/2015/countries/black-sea. [Accessed 11th May 2020]

De Groot, R.S. (2010) Challenges in integrating the concept of ecosystem services and values in landscape planning, management and decision making // Ecol. Complex. - 2010. - Vol. 7. - P. 260-272

Edward, B., Barbier. (2017) Marine ecosystem services // Current Biology, Volume 27, Issue 11, 5 June 2017, Pages R507-R510

Komorin V. 2015. Development of scenarios for improving the quality of coastal waters of the Gulf of Odessa on the basis of mathematical modeling: report on the SR / UkrSCES; Odesa. 97.

Komorin, V. M., Pavlenko, M. Yu., Verlan, V. A., Denga, Yu. M., Dudnik, D.S., Krasota, L. L., Melnik, Ye. A., Orlova, I. G., Popov, Yu. S., Rachinska, O. V., Terenko, G. V., Ukrainskyi, V.V. (2017) Ukrainian Lower Danube water assessment/ Technical report "Inventory, Assessment and Remediation of Anthropogenic Sources of Pollution in the Lower Danube Region of Ukraine, Romania and the Republic of Moldova", UkrSCES. - Odesa, 2017. 282.

Komorin, V., Popov Yu., Ukrainskyi, V. (2008) Assessment of variability of hydrodynamic characteristics of the north-western shelf of the Black Sea // Bulletin of Odesa State Ecological University. № 5. 188 - 201.

Komorin, V., Tuchkovenko, Yu. (2002) Using a numerical hydrodynamic model to predict sea level fluctuations in the ports of the northwest shelf of the Black Sea. Meteorology, climatology, hydrology, 46. 324-331.

Liquete, C., Piroddi, C., Drakou, E. G., Gurney, L., Katsanevakis, S., Charef, A., Egoh, S. (2013) Current Status and Future Prospects for the Assessment of Marine and Coastal Ecosystem Services: A Systematic Review // Review of Marine and Coastal Ecosystem Services. - July 2013. - Vol. 8, Is. 7. - 15 p.

Maes, J., Liquete, G., Teller, A., Erhard, M., Paracchini, M.-L., Barredo, C. J. I., Grizzetti, B., Cardoso, A., Somma F., Petersen J.-E., Meiner, A., Gelabert, E., Zal, N., Kristensen, P., Bastrup-Birk, A.,Biala, K., Piroddi, C., Egoh, B. N., Degeorges, P., Fiorina, C., Santos-Martín F., Naruševičius, V., Verboven. J., Pereira, H. M., Bengtsson, J., Gocheva, K., Marta-Pedroso C., Snäll, T., Estreguil, C., San-Miguel-Ayanz, J., Perez-Soba, M., Grêt-Regamey, A., Lillebo A., Malak, D. A., Condé, S., Moen, J., Czúcz, B., Drakou, E., Zulian, G., Lavalle, C. (2016) An indicator framework for assessing ecosystem services in support of the EU Biodiversity Strategy to 2020/ Ecosystem Services 17 (2016). P. 14-23: http://creativecommons.org/licenses/by/4.0. - 10.09.2018.

May, R. M. (1974) Patterns of species abundance-Mathematical aspects of dynamics of populations. SIAM Review, 16, 585-585. 
Nikolis, G., Prigogine, I. (1989) Exploring Complexity: An Introduction. W. H. Freeman and Company, New York. 352

Odum, Eugene P. (1953) Fundamentals of ecology. Philadelphia: W. B. Saunders Company, 1953. 383.

Orlova, I, Pavlenko, N., Ukrainkyi, V., Popov, Y., Matsokin, L., Komorin, V., Gavrilova, T., Lisovskyi, R., Baryshevska, G. (2005) Hydrological and hydrochemical indicators of the state of the northwest shelf of the Black Sea: reference book /- Odesa: UkrSCES, 2005. 616.

Addison, P. F. E., Collins, D. J. R., Trebilco, Howe, S., Bax, N., Hedge, P., Jones, G., Miloslavich, P, Roelfsema, C., Sams, M., Stuart-Smith, R. D., Scanes, P., Baumgarten P., McQuatters-Gollop A. (2018) A new wave of marine evidence-based management: emerging challenges and solutions to transform monitoring, evaluating, and reporting ICES Journal of Marine Science, Volume 75, Issue 3, May-June 2018, Pages 941-952, https://doi.org/10.1093/icesjms/fsx216

Park, R.A., Clough, J.S. (2003) AQUATOX for Windows: A Modular Fate and Effects Model for Aquatic Ecosystems: Perfluoroalkylated Surfactant and Estuarine Versions, Addendum to Release 2 Technical Documentation. EPA 823-R-04-001, U.S. Environmental Protection Agency, Washington, DC.

Polderman, J.W., Willems, J.C. (1998) Stability Theory. In: Introduction to Mathematical Systems Theory. Texts in Applied Mathematics, vol 26. Springer, New York, NY. https://doi.org/10.1007/978-1-4757-2953-5_7

Fulford, R. S., Heymans, S. J. J., Wei, Wu. (2020) Mathematical Modeling for Ecosystem-Based Management (EBM) and Ecosystem Goods and Services (EGS) Assessment // Ecosystem-Based Management, Ecosystem Services and Aquatic Biodiversity pp 275-289

Şimşek, A., Küçük, K., Bakan, G. (2019) Applying AQUATOX for the ecological risk assessment coastal of Black Sea at small industries around Samsun, Turkey // International Journal of Environmental Science and Technology. -2019. Volume 16, p. $5229-5236$

Slobodnik, J., Alexandrov, B., Komorin, V., Mikaelyan, A., Guchmanidze, A., Arabidze, M., Korshenko, A., Moncheva, S. (2020a) National Pilot Monitoring Studies and Joint Open Sea Surveys in Georgia, Russian Federation and Ukraine, 2016: Final Scientific Report / J. Slobodnik, B. Alexandrov, V. Komorin, A. Mikaelyan, A. Guchmanidze, M. Arabidze6 A. Korshenko, S. Moncheva. - Dnipro: Seredniak T.K. [Online] Available from: http://emblasproject.org/wp-content/uploads/2018/08/EMBLASII_NPMS_JOSS_2016_ScReport_Final3.pdf

Slobodnik, J., Medinets, V., Alexandrov, B., Komorin, V., Mikaelyan, A., Guchmanidze, A., Arabidze, M., Korshenko, A. (2020b). 12-Months National Pilot Monitoring Studies in Georgia, Russian Federation and Ukraine, 2016-2017: Final Scientific Report/ J. Slobodnik, V. Medinets, B. Alexandrov, V. Komorin, A. Mikaelyan, A. Guchmanidze, M. Arabidze, A. Korshenko. - Dnipro: Seredniak T.K. [Online] Available from: http://emblasproject.org/wp-content/uploads/2019/07/EMBLAS-II_NPMS_12_months2016_2017_FinDraft2.pdf

Slobodnik, J., Alexandrov, B., Komorin, V., Mikaelyan, A., Guchmanidze, A., Arabidze, M., Korshenko, A. (2020c) National Pilot Monitoring Studies and Joint Open Sea Surveys in Georgia, Russian Federation and Ukraine, 2017: Final Scientific Report / J. Slobodnik, B. Alexandrov, V. Komorin, A. Mikaelyan, A. Guchmanidze, M. Arabidze6 A. Korshenko. - Dni pro: Seredniak T.K. [Online] Available from: http://emblasproject.org/wp-content/uploads/2019/07/EMBLAS-

II_NPMS_JOSS_2017_ScReport_FinDraft2.pdf

Svirezhev, Yu. (1974) Possible ways to generalize the fundamental theorem of natural selection by R. Fischer // Journal of General Biology. - 1974. - T. 35, № 4. 590-601

TISEAN 3.0.1. (2018) Nonlinear Time Series Analysis. [Online] http://www.mpipksdresden.mpg.de/ tisean/Tisean_3.0.1 /index.html. - 12.11.18.

Tuchkovenko, Yu., Ilyushin V., Komorin, V. (2005) Simulation of the transport of sediments in the Kerch Strait. Meteorology, climatology, hydrology, 49. 446-459. 